\section{CAPACIDAD PREDICTIVA DEL PROCESO DE ADMISIÓN EN EL DESEMPEÑO ACADÉMICO DE LOS ESTUDIANTES DE MEDICINA}

\section{PREDICTIVE CAPACITY OF UNIVERSITY ADMISSION PROCESS IN THE FUTURE ACADEMIC PERFORMANCE OF MEDICAL STUDENTS}

\author{
Fernando Munayco-Guillén ${ }^{1,2, a}$, Anaís Cámara-Reyes ${ }^{1,2, a}$
}

Sr. editor. A partir del siglo XXI la educación universitaria ha enfrentado grandes transformaciones, debido al impacto de la globalización y a los cambios científicos, económicos y sociales. La universidad ha tenido que adaptarse a dicha transformación y para ello debe someter a sus aspirantes a un proceso de admisión que brinde a la sociedad profesionales idóneos y capaces de resolver problemas en su realidad $^{(1)}$.

La carrera de medicina humana exige a sus estudiantes máxima dedicación respecto al tiempo y esfuerzo, además de una serie de cualidades como madurez, responsabilidad e integridad. Se espera que una persona que cumpla con estos requisitos pueda superar las dificultades de la carrera médica y sea un buen profesional ${ }^{(2)}$.

La expresión que permite conocer la existencia de calidad en la educación a cualquier nivel es el rendimiento académico, que es definido como la capacidad de respuesta que tiene un individuo a estímulos, objetivos y propósitos educativos previamente establecidos, permitiendo conocer el éxito o fracaso en el estudio a través de calificativos ${ }^{(3)}$.

El problema fundamental del proceso de admisión es su capacidad predictiva sobre el futuro rendimiento académico del universitario, teniendo en cuenta el puntaje obtenido en dicho proceso. Investigaciones realizadas en diversos países señalan que este proceso no asegura que los seleccionados puedan ser competentes para afrontar las exigencias de la carrera de medicina (2)

Las consecuencias de un proceso de admisión con baja capacidad predictiva son: repitencia, retraso y deserción de la carrera, que trae consigo frustración para el estudiante y pérdidas económicas para la familia, la institución universitaria y el estado ${ }^{(4)}$.

En la investigación realizada por Castaño et al ${ }^{(4)}$, concluyeron que dentro de su sistema de admisión la prueba del Instituto Colombiano para el Fomento de la Educación Superior (ICFES), que mide el rendimiento académico anterior, es un buen predictor de buen rendimiento académico solo para el primer nivel de la carrera.

En Chile, Bastías et al. ${ }^{(2)}$, encontraron que existe una correlación significativa entre las notas de la secundaria y el rendimiento académico universitario. Mientras que Wilkinson et al. ${ }^{(5)}$, evaluaron la prueba de admisión a las Ciencias de Salud (UMAT). Los resultados indican que es un buen predictor para los primeros años de estudio, pero no para los años clínicos, ni para predecir el desempeño profesional.

\footnotetext{
${ }^{1}$ Facultad de Medicina Humana. Universidad San Luis Gonzaga, Ica, Perú.

${ }^{2}$ Sociedad Científica de Estudiantes de Medicina de Ica (SOCEMI).

${ }^{3}$ Estudiante de Medicina
}

Piscoya ${ }^{(6)}$, nos señala que la Universidad Nacional San Agustín de Arequipa, es una de las universidades del Perú que tiene un proceso de admisión distinto a la de las demás universidades. En estudios realizados en dicha universidad se encontró escasa correlación y valor predictivo casi nulo entre el proceso de admisión y el rendimiento académico, hallando que el $50 \%$ de estudiantes no termina la carrera en el tiempo previsto y el $30 \%$ son estudiantes irregulares.

Como se puede observar la mayoría de trabajos coincide en que el rendimiento académico previo es la única variable que tiene correlación con el rendimiento académico futuro. Se debe tener en cuenta que este poder predictivo de los procesos de admisión, son buenos para los primeros años de carrera, pero no para los años clínicos y quirúrgicos, ya que estos se van perdiendo conforme se avanza en la carrera. Sería ideal diseñar un proceso de admisión con instrumentos que puedan tener una buena capacidad predictiva hasta el final de la carrera y que varíen mínimamente a causa de los factores humanos psicológicos y conductuales del estudiante.

Por lo expuesto, sugerimos que este tema se encuentre en constante estudio a través de investigaciones realizadas en el Perú, porque de ello depende la selección de buenos estudiantes, que puedan asegurar su éxito académico, científico y profesional.

Conflictos de interés: los autores declaran no tener conflictos de interés en la publicación de este artículo.

\section{Correspondencia:}

Fernando Munayco Guillén

Correo electrónico: fernandomg345@hotmail.com

\section{REFERENCIAS BIBLIOGRÁFICAS.}

1. Cortés A y Palomar J. El proceso de admisión como predictor del rendimiento académico en la educación superior. Universitas Psychologica 2008; 7(1):197-213.

2. Bastias G, Villaroel L y Zuñiga D. Desempeño académico de los estudiantes de medicina: ¿Un resultado predecible? Rev. méd. Chile 2000; 128(6):671-678.

3. Jara D, Velarde H y Gordillo G. Factores influyentes en el rendimiento académico de estudiantes del primer año de medicina. An Fac med 2008; 69(3): 196-197.

4. Castaño J. Correlación entre criterios de admisión, y desempeño académico, en estudiantes de la facultad de medicina de la Universidad de Manizales Colombia. Arch. Med 2008; 8(2): 134-148.

5. Wilkinson $\mathbf{D}$, Zhang $\mathbf{J}$ y Parker $\mathbf{M}$. Predictive validity of the Undergraduate Medicine and Health Sciences Admission Test for medical students' academic performance. MJA 2011; 194(7):341-344.

6. Piscoya L. Calidad de las Pruebas de Admisión en la Universidad Peruana. UNESO-IESALC 2005.

Recibido:29/06/2012

Aceptado para publicación: 25/07/2012 